\title{
Monitoring adverse events in older hospitalized patients: A retrospective cross-sectional study using validated screening criteria with administrative data
}

\author{
Stacy A. Ackroyd-Stolarz*1, Susan K. Bowles ${ }^{2,3}$, Lorri Giffin ${ }^{4}$ \\ ${ }^{1}$ Department of Emergency Medicine, Dalhousie University, Halifax, Nova Scotia, Canada \\ ${ }^{2}$ Geriatric Medicine, Nova Scotia Health Authority, Halifax, Nova Scotia, Canada \\ ${ }^{3}$ College of Pharmacy and Division of Geriatric Medicine, Dalhousie University, Halifax, Nova Scotia, Canada \\ ${ }^{4}$ South Shore Family Health, Bridgewater, Nova Scotia, Canada
}

Received: July 26, 2018

DOI: $10.5430 /$ jha.v7n6p7
Accepted: October 4, 2018

URL: https://doi.org/10.5430/jha.v7n6p7

\begin{abstract}
Objective: Older patients are at higher risk of experiencing an adverse event (AE) during an acute hospitalization. The objective of the current study was to use routinely collected administrative data to characterize AEs and their system-level impact for older patients hospitalized in one Canadian health authority.

Methods: This retrospective cross-sectional study occurred in the Capital District Health Authority in Nova Scotia, Canada between April 1, 2012 and March 31, 2013. The primary outcome was identification of pressure ulcers, fall-related injuries and adverse drug events in patients 65 years of age and older admitted to an acute inpatient service. AEs were identified using validated screening criteria. Data were analyzed using standard descriptive statistics.

Results: There were 11,747 hospitalizations during the study period. A total of 330 (2.8\%) AEs in 325 patients were identified using the screening criteria. This included 55 (16.7\% of 330) pressure ulcers, 25 (7.6\%) fall-related injuries and 250 (75.8\%) adverse drug events. The average length of stay was significantly higher in patients with a pressure ulcer $(35.8 \pm 47.3 \mathrm{vs} .9 .0 \pm$ 14.8 days, $p<.0001)$, fall-related injury (30.3 \pm 23.2 vs. $9.0 \pm 15.2$ days, $p<.0001)$, or adverse drug event $(14.6 \pm 14.4$ vs. 9.0 \pm 15.2 days, $p<.0001)$ during their acute hospitalization.

Conclusions: Use of validated screening criteria with administrative hospitalization data provides important information for monitoring the system-level impact of common AEs in older patients. Significant and clinically important differences in healthcare utilization underscore the value in monitoring these AEs in this growing patient population.
\end{abstract}

Key Words: Geriatrics, Patient safety, Adverse drug events, Pressure ulcers, Fall-related injuries

\section{INTRODUCTION}

Patient safety has become a critical focus for healthcare organizations and accreditation bodies in the last two decades. International patient safety studies have consistently identified older people (65 years of age and older) as a patient population with an elevated risk of experiencing unintended harm while in hospital. ${ }^{[1-3]}$ The increased risk is related to many factors including, but not limited to higher rates of co-morbidities, functional loss, medication and health service utilization. ${ }^{[1-3]}$ This is clinically, administratively and

\footnotetext{
*Correspondence: Stacy A. Ackroyd-Stolarz; Email: Stacy.Ackroyd@dal.ca; Address: Department of Emergency Medicine, Dalhousie University, QEII Health Sciences Centre, Halifax Infirmary, 1796 Summer Street, Suite 355, Halifax, Nova Scotia, B3H 3A7, Canada.
} 
financially important because it is a growing patient group that healthcare systems around the world are struggling to safely manage.

The term adverse event (AE) has been used to describe unintentional harm caused by medical care rather than the patient's underlying disease. ${ }^{[2]}$ Although new terminology has been adopted to describe healthcare-related harm, at the time of the study the term AE was used. Common types of AEs experienced by older patients in hospital include pressure ulcers, fall-related injuries and adverse drug events. Hospital accreditation standards include required organizational practices and national patient safety goals related to the prevention of these types of AEs. ${ }^{[4,5]}$ The tests for compliance highlight the need for monitoring mechanisms in order to measure performance and the effectiveness of improvement strategies.

Integral to the development of effective monitoring capability is the availability of reliable data. Approaches to monitoring AEs include incident reporting systems, trigger tools, retrospective health record reviews, computerized alert systems and analysis of routinely collected administrative data. Each approach has its strengths and limitations. ${ }^{[6,7]}$ In trying to identify the optimal approach, there is inevitably a compromise between clinical detail, availability of system-level information and the data collection burden. The best monitoring approach and source(s) of data depend on the intended purpose but none are definitive. It has been argued that using multiple approaches to monitoring and use of a variety of data sources will give a more comprehensive view of the problem. ${ }^{[6-8]}$ Notably, AE monitoring has often reflected the changing focus in patient safety. Error was a predominant focus in early studies however this has shifted to a broader focus on systems and harm. ${ }^{[9,10]}$ The distinction between harm and error is important because the data source, monitoring approach and calculation of the economic burden may differ depending on the focus.

The Agency for Healthcare Research and Quality (AHRQ) funded early research that employed two different approaches to monitoring patient safety, one with a focus on errors and the other on patient injury or harm. The approaches are similar in that they are both based on diagnostic codes from the International Classification of Diseases (ICD) and are used with administrative hospitalization data. They differ in terms of the number and type of diagnostic codes and the exclusion criteria used in their case definitions. Specifically, the AHRQ Patient Safety Indicators (PSI) were developed to identify different types of potentially preventable AEs and those associated with errors. ${ }^{[6]}$ For example, one of the PSIs is for decubitus or pressure ulcers. The PSI for pressure ulcers has excluded patients with a pressure ulcer that is present on admission to ensure identification of those that occur during hospitalization and are thus potentially related to care in-hospital. ${ }^{[11]}$ While this is a valuable safety indicator, the strict exclusion criteria do not allow a complete enumeration of the financial burden associated with pressure ulcers in all patients.

The second monitoring approach funded by AHRQ focused on patient injury or harm and adopted a public health/surveillance framework to identify AEs using screening criteria based on diagnostic codes in administrative data. ${ }^{[10,12]}$ The monitoring approach using a surveillance framework differs from the PSIs in that it has fewer exclusion criteria and uses a broader range of diagnosis codes, including medication-related codes. The case definition for pressure ulcers demonstrates the differences. In the former, patients with paralysis are also excluded in the PSI definition so as to restrict the indicator to pressure ulcers that are potentially preventable and not necessarily attributable to a person's medical condition. ${ }^{[11]}$ A monitoring approach that uses a surveillance framework does not exclude patients with pre-existing pressure ulcers and/or paralysis. A main administrative advantage to surveillance is improved capability for determining the overall costs associated with AEs such as pressure ulcers even if they are not potentially preventable or associated with error. As with any approach that utilizes administrative data, the surveillance approach has its unique limitations in terms of the quality and consistency of the coding. For example, coding standards require physician documentation to code a diagnosis. The documentation by physicians for some conditions such as pressure ulcers is often limited and therefore, these AEs are not always captured in the diagnostic codes in administrative data. ${ }^{[11,13]}$ Screening criteria or flags for specific AEs derived from diagnostic codes found in administrative data have been validated in the US using ICD-9-CM ${ }^{[10,12]}$ and in Canada using ICD-10CA ${ }^{[14]}$ Administrative data have been used more commonly for surveillance of adverse drug events, but have also been used to monitor other types of AEs. ${ }^{[6,15-17]}$ Although the use of screening criteria for patient harm has not been as widely adopted as the AHRQ PSIs, this approach has the potential to augment what is known from other sources such as incident reporting systems and offers an alternative for organizations that do not use the PSIs. However, it is not known if validated screening criteria for commonly occurring AEs in older patients admitted to acute care will yield information that is useful for informing organizational efforts to improve patient safety for this rapidly growing patient population. The objective of the current study was to use routinely collected administrative data to characterize AEs 
and their system-level impact in older patients hospitalized in one provincial health authority in Canada.

\section{METHODS}

\subsection{Design and setting}

This retrospective cross-sectional study took place in the former Capital District Health Authority (CDHA) in Nova Scotia, Canada between April 1, 2012 and March 31, 2013. Capital Health (currently the Central Zone of the Nova Scotia Health Authority) has approximately 34,400 admissions to acute care annually for patients of all ages in six different facilities. The inpatient facilities include five community hospitals and an academic health sciences centre. The latter has approximately 1,100 beds and manages the majority of acute admissions for the health authority. The study was reviewed and approved by the CDHA Research Ethics Board.

\subsection{Population}

Older patients ( $\geq 65$ years) discharged from any of the CDHA acute inpatient units between April 1, 2012 and March 31, 2013 were eligible for inclusion in the study. For patients with more than one hospitalization during the study period, only the first hospitalization was included. Patients who spent any time in an alternate level of care (ALC) during their hospital admission were excluded from the study as they represent a distinct patient population.

\subsection{Data source}

De-identified administrative hospitalization data were obtained from the Discharge Abstract Database (DAD) for a one-year fiscal period. For the DAD database, trained health information management professionals abstract and code information from a patient's hospital record using Canadian coding standards for the ICD, Tenth Revision, Canada (ICD-10-CA). The timeframe was selected in order to eliminate bias from seasonal variation and to generate populationbased data on hospitalizations. The data included information on demographics (e.g., age, gender), clinical course (e.g., diagnoses, diagnosis type indicators, co-morbidities, admission to an intensive care unit), utilization (e.g., length of stay) and disposition (e.g., discharge to nursing home) for all patients admitted to any of the acute care inpatient services at any of the hospitals within CDHA. The data included up to 25 diagnoses per patient and a diagnosis type indicator for each diagnosis. In Canada, a diagnosis type indicator is used to distinguish between conditions that were present at the time of admission (Type 1) and those that develop during a hospitalization (Type 2). ${ }^{[18]}$

Published by Sciedu Press

\subsection{Outcome measure}

Consistent with a surveillance approach, the primary outcome was an AE identified in administrative diagnostic data using previously validated screening criteria. ${ }^{[10,14]}$ Adverse drug events were identified using the diagnostic codes developed by the Wisconsin Medical Injury Prevention Program (WMIPP). ${ }^{[10]}$ Their screening criteria use a combination of the ICD (ICD-9-CM) diagnosis and external cause of injury codes applied to administrative data. The diagnosis code describes the nature of the problem (e.g., localized skin eruption) and the external cause of injury codes identify the mechanism (e.g., adverse effect of antibiotic). In comparison with retrospective health record review by a clinician, a US-based validation study determined the screening criteria were $59.9 \%$ sensitive (95\% CI 42.8-75.0) and $97.4 \%$ specific (95\% CI 94.1-98.8). ${ }^{[10]}$ In a validation study using Canadian data and other geriatric-specific screening criteria using ICD, Tenth Revision, Canada (ICD-10-CA) diagnostic codes for pressure ulcers, adverse drug events and fall-related injuries had an overall sensitivity and specificity exceeding 0.67 (95\% confidence interval: $0.56-0.99)$ and 0.89 (95\% CI: 0.72-0.99) respectively. ${ }^{[14]}$

The Discharge Abstract Database includes text descriptions of diagnostic codes. The text descriptions were compared with ICD codes for all positive records and only those that matched were considered to be positive for an AE. Information from text was included to minimize misclassification and to exclude AEs that were intentional in nature for adverse drug events. To be considered an $\mathrm{AE}$ related to the current hospitalization, the diagnosis type indicator had to be a Type 2 - indicating that the event occurred after hospital admission. ${ }^{[18]}$ Comorbid conditions were identified using the Elixhauser method to ensure consistency and completeness. ${ }^{[19]}$ Secondary outcome measures included hospital length of stay and disposition for those with and without an $\mathrm{AE}$ (as determined by the diagnostic code). The secondary outcome measures were intended to provide information on the potential usefulness of this specific monitoring approach in terms of informing organizational safety and quality initiatives.

\subsection{Data analysis}

Descriptive statistics were generated using STATA statistical software (STATA Corp., College Station TX, Version 9). Differences between those with and without an AE were compared using the $\chi^{2}$ test for categorical data, an unpaired $t$-test for normally distributed continuous data and the Mann Whitney $U$-test for data that were not normally distributed. Data were not analyzed by hospital site as the number of eligible patients at some of the smaller community hospitals 
was low. The reporting of the study adheres to the guidelines for strengthening the reporting of observational studies in epidemiology (STROBE). ${ }^{[20]}$

\section{ReSUlts}

There were 11,747 eligible patients discharged from any of the CDHA acute inpatient units during the study period. A total of $330(2.8 \%)$ AEs in 325 patients were identified us- ing the surveillance criteria. This included 55 (16.7\% of 330) pressure ulcers, 25 (7.6\%) fall-related injuries and 250 (75.8\%) adverse drug events. All of the adverse drug events were coded as "adverse effects in therapeutic use" (Y40Y59). The medications most commonly implicated in an AE were anti-coagulants $(\mathrm{N}=34)$, opioids and related analgesics $(\mathrm{N}=31)$, other neoplastic drugs $(\mathrm{N}=29)$, and nonsteroidal anti-inflammatory drugs $(\mathrm{N}=22)$.

Table 1. Clinical and demographic characteristics by AE status for patients $\geq 65$ years discharged from acute care services at Capital Health between April 1, 2012-March 31, 2013

\begin{tabular}{|c|c|c|c|}
\hline Parameter & No AE $(N=11,422)$ & Any AE $(N=325)$ & $p$-value \\
\hline \multicolumn{4}{|l|}{ Demographics } \\
\hline Mean age in years $(S D)^{*}$ & $75.8(7.9)$ & $76.5(7.8)$ & $\mathrm{NS}^{* *}$ \\
\hline Female & $5,492(48.1 \%)$ & $157(48.3 \%)$ & NS \\
\hline \multicolumn{4}{|l|}{ Pre-existing co-morbidities ${ }^{* * * *}$} \\
\hline Any co-morbidity? (Y/N) & $2,854(25.0 \%)$ & $148(45.5 \%)$ & $<.0001$ \\
\hline Average \# of co-morbidities ( $S D$ ) & $0.3(0.7)$ & $0.7(0.9)$ & $<.00001$ \\
\hline Fluid \& electrolyte disturbance & $477(4.2 \%)$ & $36(11.1 \%)$ & $<.0001$ \\
\hline Congestive heart failure & $481(4.2 \%)$ & $27(8.3 \%)$ & $<.0001$ \\
\hline Diabetes, complicated & $291(2.6 \%)$ & $15(4.6 \%)$ & .02 \\
\hline Renal disease & $92(0.8 \%)$ & $7(2.2 \%)$ & .009 \\
\hline Pulmonary circulation disorders & $82(0.7 \%)$ & $8(2.5 \%)$ & $<.0001$ \\
\hline Weight loss & $55(0.5 \%)$ & $7(2.2 \%)$ & $<.0001$ \\
\hline Liver disease & $32(0.3 \%)$ & $3(0.9 \%)$ & .04 \\
\hline Depression & $32(0.3 \%)$ & $3(0.9 \%)$ & .04 \\
\hline Peptic ulcer disease & $9(0.1 \%)$ & $2(0.6 \%)$ & .002 \\
\hline \multicolumn{4}{|l|}{ Most responsible diagnosis ${ }^{* * * *}$} \\
\hline Circulatory & $3,099(27.1 \%)$ & $66(20.3 \%)$ & .006 \\
\hline Musculoskeletal & $1,048(9.2 \%)$ & $12(3.7 \%)$ & .001 \\
\hline \multicolumn{4}{|l|}{ Clinical course } \\
\hline Ventilator use (Y/N) & $817(7.2 \%)$ & $32(9.9 \%)$ & NS \\
\hline ICU stay $(\mathrm{Y} / \mathrm{N})$ & $1,419(12.4 \%)$ & $51(15.7 \%)$ & NS \\
\hline Palliative (Y/N) & $540(4.7 \%)$ & $35(10.8 \%)$ & $<.0001$ \\
\hline \multicolumn{4}{|l|}{ System-related } \\
\hline EMS transport $(\mathrm{Y} / \mathrm{N})$ & $5,058(44.3 \%)$ & $193(59.4 \%)$ & $<.0001$ \\
\hline Main patient service - surgical $(\mathrm{Y} / \mathrm{N})$ & $5,535(48.5 \%)$ & $79(24.3 \%)$ & $<.0001$ \\
\hline Mean ICU LOS in days $(S D)$ & $0.5(3.0)$ & $1.3(5.1)$ & $<.02$ \\
\hline
\end{tabular}

Note. ${ }^{*}$ Standard deviation; ${ }^{* *}$ Not significant; ${ }^{* * *}$ Only diagnoses that are significant are included in this table

The baseline characteristics of the two groups (with and without an AE) are presented in Table 1. Patients who experienced an $\mathrm{AE}$ in hospital were slightly older, although the difference was not significant. Those with one or more preexisting co-morbidities were more likely to experience an AE. The most responsible diagnosis refers to one that has the greatest contribution to a patient's length of stay and resource use during their hospitalization. ${ }^{[18]}$ A lower proportion of pa- tients with a most responsible diagnosis related to circulatory and musculoskeletal conditions experienced an AE during their hospitalization. There was a higher proportion of AEs in palliative patients, those transported to hospital by EMS and those admitted to a non-surgical service.

The average length of stay was significantly higher in patients experiencing a pressure ulcer $(35.8$ vs. 9.0 days, $p<.0001)$, 
fall-related injury (30.3 vs. 9.0, $p<.0001$ ), or adverse drug event (14.6 vs. 9.0 days, $p<.0001$ ), during their hospitalization. Table 2 includes a calculation to demonstrate the incremental effect of an $\mathrm{AE}$ on hospital length of stay for the study patients. The differences in average length of stay are smallest for patients with adverse drug events. However this is countered by the high frequency of adverse drug events relative to the other types of AEs. Although the majority of patients were discharged home with no support, there was a significantly lower proportion for patients with an AE (see Table 3). This group was also more likely to require support if discharged home and to be transferred to continuing care. The proportion of patients who died during their hospitalization was significantly higher amongst patients with an AE.

Table 2. Hospital length of stay by type of AE for patients $\geq 65$ years discharged from acute care services at Capital Health between April 1, 2012-March 31, 2013

\begin{tabular}{llllll}
\hline \multirow{2}{*}{ Adverse Event Status } & \multirow{2}{*}{ Number of Events } & \multicolumn{3}{c}{ Hospital Length of Stay in Days } \\
\cline { 3 - 5 } & & Average & Median & Range & \multirow{2}{*}{ Total \# of Excess Days } \\
\hline No adverse event & 11,422 & 8.8 & 5 & $1-423$ & -- \\
Pressure ulcer & 55 & 35.8 & 23 & $1-317$ & 1,485 \\
Adverse drug event & 250 & 14.6 & 9 & $1-74$ & 1,450 \\
Fall-related injury & 25 & 30.3 & 27 & $1-84$ & 537.5 \\
\hline
\end{tabular}

Note. ${ }^{*}$ Calculation: (Average LOS by type of AE - Average LOS for no AE) $\times$ Number of events by type of AE $=$ Total \# of Excess Days (e.g., for pressure ulcers: $[35.8-8.8] \times 55=27 \times 55=1,485)$

Table 3. Comparison of discharge disposition by AE status in patients $\geq 65$ years discharged from acute care services at Capital Health April 1, 2012-March 31, 2013

\begin{tabular}{llll}
\hline Parameter & No AE $(\boldsymbol{N = 1 1 , 4 2 2})$ & Any AE $(\boldsymbol{N}=\mathbf{3 2 5})$ & $p$-value \\
\hline Discharge Disposition & & & $<.0001$ \\
Discharge home, no support & $6,913(60.5 \%)$ & $134(41.2 \%)$ & $<.0001$ \\
Discharge to home setting with support & $1,989(17.4 \%)$ & $86(26.5 \%)$ & $\mathrm{NS}{ }^{*}$ \\
Transfer to acute inpatient care & $1,199(10.5 \%)$ & $37(11.4 \%)$ & .02 \\
Transfer to continuing care & $385(3.4 \%)$ & $19(5.9 \%)$ & $<.0001$ \\
Death & $878(7.7 \%)$ & $36(14.2 \%)$ & $\mathrm{NS}$ \\
Other & $58(0.5 \%)$ & $3(0.9 \%)$ & \\
\hline
\end{tabular}

Note. ${ }^{*}$ Not significant

\section{Discussion}

\subsection{Patient safety and the aging population}

The aging population is a critical consideration for the patient safety and quality improvement efforts of healthcare organizations globally. Older patients have higher rates of healthcare utilization and a demonstrated increase in the risk of experiencing unintended harm in healthcare. ${ }^{[1-3]}$ Although our study focused on three types of AEs, other types of harm have also been described such as urinary tract infection and delirium. ${ }^{[17]}$ The literature reports highly variable rates of pressure ulcers $(3.0 \%-25.1 \%)^{[21,22]}$ and fall-related injuries (4.1-10.0 falls per 1,000 patient days) ${ }^{[23]}$ in older adults in acute care. This is likely due to the differences in study methods and case-finding definitions. Other studies that utilized similar screening criteria and methods as the current study were not restricted to patients 65 years and older, thus Published by Sciedu Press making direct comparison difficult. ${ }^{[10,12]}$

In one Australian retrospective cohort study of potentially preventable in-hospital complications in patients over the age of $50,4.2 \%$ of medical patients and $4.9 \%$ of surgical patients had a pressure ulcer. The study used administrative hospital discharge data and previously published "coding rules" to identify cases, including exclusion of patients with hemiplegia or quadriplegia. ${ }^{[17]}$ This differed from our study in that we included patients 65 years and older and did not exclude those with paralysis. In a US study of 500,000 randomly selected hospital discharge records, there were $109(0.02 \%)$ pressure ulcers identified in administrative data. While this is lower than our finding of 55 pressure ulcers in 11,747 patients $(0.5 \%)$, the US study differed in that it included all adult admissions and identified only the most serious pressure ulcers (Stage III or IV). ${ }^{[15]}$ In the same study, there were 
$190(0.04 \%)$ patients with a fall-related injury. ${ }^{[15]}$ Waters et al. compared fall-related injuries identified through an incident reporting system with administrative hospital discharge data in 16 surgical and medical units for adults in one US teaching hospital. There were 2,406 falls identified (2.4\% of patient stays) of which 380 resulted in an injury ( $0.4 \%)$. Their case definition for fall-related injuries found in administrative data was restricted to predominantly orthopaedic injuries and missed cases involving other types of injuries (e.g., intracranial hemorrhage) that were included in records from the incident reporting system. ${ }^{[16]}$ Our study finding of $0.2 \%$ of patients experiencing a fall-related injury is within the range reported in these studies, but caution must still be exercised given the variability in the diagnostic codes and exclusion criteria used in case definitions. This is particularly evident for monitoring adverse drug events where case definitions are even more variable.

A systematic review identified a total of 827 ICD-10 codes that have been used in published literature to describe adverse drug events. ${ }^{[24]}$ This large range offers potentially important codes that will help to identify adverse drug events, but also makes comparisons problematic. In a German study using ICD-10-GM codes for adverse drug events identified in administrative hospitalization data, approximately $0.7 \%$ of admissions were caused by adverse drug events. A further 5.3\% of hospital admissions were associated with an adverse drug event, but causality was not established. It is not possible to compare this directly to our study in that the German study included all adult admissions. ${ }^{[25]}$ In a previous study at one of the hospitals in the same organization and using the same screening criteria as the current study, there were 26 adverse drug events identified in $982(2.6 \%)$ patients 65 years and older admitted to acute care. ${ }^{[26]}$ This is consistent with the current study results of 250 ( $2.1 \%$ of 11,747$)$ adverse drug events. The finding of a higher proportion of adverse drug events relative to other types of AEs is consistent with other literature. ${ }^{[2]}$ Although there is variability in study methods and case definitions, the consistency of this finding likely reflects higher use of medications and physiologic changes that predispose older adults to unintended effects of certain medications. ${ }^{[27]}$

The consequences of AEs are more significant in older patients, in part due to diminished physiologic reserve and resiliency, although this is not necessarily evident from the relatively low number of comorbidities found in our study population. $^{[2,27]}$ The significant personal cost to patients is reflected in the differences we found in disposition and length of stay for those experiencing an AE. They were less likely to be discharged home and more likely to need support upon discharge or to be transferred to continuing care.
Regardless of the type of unintended harm identified in our study, patients experiencing an AE had a significantly longer length of stay in hospital. This has been a consistent finding in other patient safety studies involving older adults. ${ }^{[1,2,15]}$ It is important to note that we were unable to ascertain a causal relationship. More advanced analyses are needed to control for confounding factors in order to strengthen our understanding of the association between AEs and utilization data. Although our results are preliminary, the differences in our secondary outcome measures suggest that the screening criteria can yield potentially useful information for an organization to identify AEs and to monitor the effectiveness of improvement activities. Our study focused on acute care only by excluding patients who had been transferred to an ALC while awaiting placement in a long-term care facility. Thus the prolonged length of stay for those patients experiencing an AE illustrates the opportunity cost of AEs in terms of the availability of acute care beds. This has important implications for the healthcare system.

\subsection{System-level impact of AEs}

Hospitals frequently experience higher volumes of older adults seeking care. This is compounded by limited availability of acute care beds for those needing to be admitted. As a result, admitted patients are often boarded in the emergency department until a hospital bed becomes available. This has contributed to levels of emergency department crowding that have reached crisis levels in many jurisdictions. ${ }^{[28]}$ Although the results of the study do not confirm a causal relationship between AEs and a prolonged hospital stay it demonstrates the importance of monitoring AEs to determine the nature and impact of the problem, identify potentially modifiable risk factors and evaluate the effectiveness of prevention strategies.

An acknowledged challenge in monitoring patient safety for older patients is distinguishing an $\mathrm{AE}$ from disease progression. ${ }^{[1]}$ Understanding potentially modifiable contributors to hospital length of stay is one practical example of the challenge. In our study, there was a positive association between hospital length of stay and all types of AEs. What is less clear, is the extent to which the increased length of stay is directly attributable to the $\mathrm{AE}$ rather than to age-related factors (e.g., functional decline), however it is likely a combination of the two. Although it was beyond the scope of this study, the use of administrative data enables a population-based approach to monitoring that permits an objective determination of the relative contributions of various factors by generating adjusted risk estimates which control for other common age-related factors such as pre-existing co-morbidities.

Organizations monitor patient safety in a variety of ways 
using different methods and case definitions. The ideal approach needs to be tailored to each organization and will depend on factors such as availability of data, capacity for advanced analyses, infrastructure and the data collection burden. While broadening the number of diagnostic codes and minimizing the exclusion criteria in case definitions differs from some of the more established patient safety measures such as the Patient Safety Indicators, Bankowitz et al. contend that it can provide a "more complete picture" of the harm experienced by patients and support monitoring activities. ${ }^{[15]}$ This suggests the potential for organizations to more fully utilize available data sources to inform their patient safety and quality improvement efforts.

\subsection{Capitalizing on data sources to inform patient safety and quality improvement efforts}

\subsubsection{Voluntary incident reporting systems}

Hospitals have invested substantially in infrastructure and human resources for strengthening systems for monitoring patient safety. A very common approach to monitoring is through a voluntary incident reporting system. This approach offers clinically important details about specific events. Although the number of events can be monitored over time there are several limitations with relying solely on data from a reporting system. Several studies have described the issue of under-reporting ${ }^{[6,8,29]}$ and the limited ability to calculate rates that can be monitored over time. ${ }^{[29]}$ Noble et al. describe the potential for systematic bias for certain events leading to challenges in monitoring trends. They also describe a participation bias related to higher rates of reporting by nurses compared with physicians. If data from a reporting system are the sole source for establishing organizational priorities, these biases may change the focus. ${ }^{[29]}$ However, the information gathered from reporting systems can be augmented with other sources of data.

\subsubsection{Administrative data}

Routinely collected administrative data offer another source for monitoring AEs without having to rely on active incident reporting by health care professionals. The data are coded using recognized standards and are available in many countries around the world. Core data elements typically include demographics, utilization data (e.g., LOS), procedure codes and diagnoses using ICD codes. ${ }^{[15,30]}$ Although use of administrative data to detect AEs likely under-estimates the extent of the problem, it generates important system-level information about the impact of AEs. The additional days in hospital for those experiencing a pressure ulcer or adverse drug event in our study exceeded 1,400 acute care bed days. Although we used an admittedly crude calculation to determine excess

Published by Sciedu Press days, this suggests enormous patient- and system-level costs. There is further potential to use administrative data in casecosting to refine estimates of the financial burden of AEs and cost-savings associated with prevention strategies. ${ }^{[15]}$

Administrative data have been used for surveillance of adverse drug events, fall-related injuries, hospital-acquired pneumonia and complications related to devices and procedures in several different countries. ${ }^{[6,10,12,16,25,30,31]}$ The Canadian Institute for Health Information (CIHI) in collaboration with the Canadian Patient Safety Institute (CPSI) recently developed a new measure of hospital harm. Their Hospital Harm Framework has four categories including harm associated with procedures, healthcare-associated infection, healthcare-/medications and patient accidents. CPSI built on the work by developing a guide with resources for using the Hospital Harm Measure. ${ }^{[32]}$ In the US, the Quality and Safety Review System (QSRS) is a more advanced patient safety surveillance system designed to include clinical information from health records and to permit hospitals and health systems to monitor rates of AEs and trends over time. ${ }^{[33,34]}$ Although not all countries have the infrastructure or resources for such sophisticated systems, the concept of surveillance for harm reduction can be scaled as needed in settings with more limited resources using routinely collected administrative data to augment existing sources of information on AEs.

\subsubsection{Using multiple sources of data}

Reliance on a single data source for monitoring AEs has several limitations. Studies have demonstrated only modest overlap in the number and types of AEs identified through various detection methods such as health record review and incident reporting. ${ }^{[6-8,35]}$ Certain detection methods are more likely to identify particular types of events. ${ }^{[7]}$ In their study using multiple approaches to identifying adverse drug events, Jha et al. determined that the health record review method was more likely to identify symptom-related events (e.g., change in mental status). However, it was also the most expensive and resource-intensive of the detection methods requiring 55 person-hours per week to implement. ${ }^{[35]}$ Gaps in event detection can be mitigated through "triangulation" of the data from multiple sources. ${ }^{[6]}$ Taylor et al. suggest that triangulation is a "realistic trade-off" between methods that yield important clinical detail, but with a high burden for data collection, and methods using available data. ${ }^{[6]}$ This triangulation of data from multiple sources will provide a better overall understanding of the problem and may help to identify processes and/or systems that have common contributions to AEs as well as opportunities for improvement. A practical challenge with triangulation is the need for a unique identifier (to eliminate duplicates) which may be especially 
difficult in anonymous reporting systems. Although using a variety of data sources and formats will enhance the monitoring capability, each organization will need to tailor the specific approach to their local needs taking into account available data sources and resources.

\subsection{Limitations}

This study took place in one Canadian health authority and as such, the results may not be generalizeable to other settings. This limitation is mitigated by the use of the ICD diagnostic codes and validated screening criteria as well as the inclusion of data from different types of hospitals in the health authority. Our analyses are preliminary and it is acknowledged that the differences in hospital length of stay and mortality between those with and without an AE may be due to other factors that were not controlled for in the analysis. Administrative data have known limitations including insufficient clinical detail and variability in the accuracy of the coding and the timing with respect to the presence of an AE. In Canadian hospitals, diagnosis typing is used to identify AEs present-on-admission.

\section{Conclusions}

The integration of multiple clinical and administrative data sources shows potential as a cost-effective, efficient and more comprehensive approach to the identification and ongoing monitoring of AEs. While the use of administrative data is not intended to replace existing mechanisms, it can be a particularly useful tool to support organizations in their efforts to achieve accreditation standards in terms of monitoring AEs and demonstrating the impact of prevention strategies for different types of AEs.

\section{ACKNOWLEDGEMENTS}

The authors wish to gratefully acknowledge Ms. Lisa Dillman, Nova Scotia Health Authority for her assistance with data acquisition. This study was funded by the Canadian Institutes of Health Research with a Pilot Projects in Aging Catalyst Grant.

\section{Conflicts of InTEREST Disclosure}

The authors declare they have no conflicts of interest.

\section{REFERENCES}

[1] Long SJ, Brown KF, Ames D, et al. What is known about adverse events in older medical hospital inpatients? A systematic review of the literature. Int J Qual Health Care. 2013; 25(5): 542-54. PMid: 23925507. https://doi.org/10.1093/intqhc/mzt056

[2] Merten H, Zegers M, de Bruijne MC, et al. Scale, nature, preventability and causes of adverse events in hospitalized older patients. Age Ageing. 2013; 42(1): 87-93. PMid: 23087046. https : //doi.org/10.1093/ageing/afs153

[3] Rothschild JM, Bates DW, Leape LL. Preventable Medical Injuries in Older Patients. Arch Intern Med. 2000; 160: 2717-28. PMid: 11025781. https://doi.org/10.1001/archinte.160 .18 .2717

[4] Accreditation Canada. Required organizational practices. Handbook 2017 [cited July 25 2018]. Available from: https : //accreditat ion.ca/required-organizational-practices/

[5] 2018 Hospital national patient safety goals. [cited July 252018 ] Available from: https://www.jointcommission.org/assets /1/6/2018_HAP_NPSG_goals_final.pdf

[6] Taylor JA, Gerwin D, Morlock L, et al. Triangulating case-finding tools for patient safety surveillance: a cross-sectional case study of puncture/laceration. Inj Prev. 2011; 17: 388-393. PMid: 21546524. https://doi.org/10.1136/ip.2010.029108

[7] Naessens JM, Campbell CR, Huddleston JM, et al. A comparison of hospital adverse events identified by three widely used detection methods. Int J Qual Health Care. 2009; 21(4): 301-07. PMid: 19617381. https://doi.org/10.1093/intqhc/mzp027

[8] Olsen S, Neale G, Schwab K, et al. Hospital staff should use more than one method to detect adverse events and potential adverse events: incident reporting, pharmacist surveillance and local real-time record review may all have a place. Qual Saf Health Care. 2007; 16(1):
40-4. PMid: 17301203. https : //doi .org/10.1136/qshc . 2005. 017616

[9] de Vries EN, Ramrattan MA, Smorenburg SM, et al. The incidence and nature of in-hospital adverse events: a systematic review. Qual Saf Health Care. 2008; 17: 216-23. PMid: 18519629. https://doi.org/10.1136/qshc. 2007.023622

[10] Layde PM, Meurer LN, Guse CE, et al. Patient safety monitoring: identification of medical injuries using hospital discharge data. In Henricksen K, Battles JB, Marks E, Lewin DI, eds. Advances in Patient Safety: From Research to Implementation. Rockville (MD): Agency for Healthcare Research and Quality; 2005. 119-32 p. Available from: https://www.ncbi.nlm.nih.gov/books/NBK2050 $1 /$

[11] Zrelak PA, Utter GH, Tancredi DJ, et al. How accurate is the AHRQ patient safety indicator for hospital-acquired pressure ulcer in a national sample of records? J Healthc Qual. 2015; 37(5): 287-97. PMid: 24118246. https://doi.org/10.1111/jhq. 12052

[12] Hougland P, Nebeker J, Pickard S, et al. Using ICD-9-CM codes in hospital claims data to detect adverse events in patient safety surveillance. In Henricksen K, Battles JB, Keyes MA, Grady ML, eds. Advances in Patient Safety: New Directions and Alternative Approaches. Rockville (MD): Agency for Healthcare Research and Quality; 2008. Available from: https://www.ncbi.nlm.nih.g ov/books/NBK43647/

[13] Thoroddsen A, Sigurjonsdottir G, Ehnfors M, et al. Accuracy, completeness and comprehensiveness of information on pressure ulcers recorded in the patient record. Scand J Caring Sci. 2012; 27(1): 8491. PMid: 22630335. https://doi.org/10.1111/j.1471-671 2.2012.01004.x

[14] Ackroyd-Stolarz S, Bowles SK, Giffin L. Validating administrative data for the detection of adverse events in older hospitalized patients. 
Drug Healthc Patient Saf. 2014; 13(6): 101-8. PMid: 25143755. https://doi.org/10.2147/DHPS.S64359

[15] Bankowitz RA, Doyle B, Duan M, et al. Identifying hospital-wide harm: A set of ICD-9-CM-coded conditions associated with increased cost, length of stay, and risk of mortality. Am J Med Qual. 2014; 29(5): 373-80. PMid: 24081831. https://doi.org/10.1 $177 / 1062860613503896$

[16] Waters TM, Chandler AM, Mion LC, et al. Use of International Classification of Diseases, Ninth Revision, Clinical Modification, codes to identify inpatient fall-related injuries. J Am Geriatr Soc. 2013; 61: 2186-91. PMid: 24329820. https://doi.org/10.1111/jgs. 12 539

[17] Bail K, Goss J, Draper B, et al. The cost of hospital-acquired complications for older people with and without dementia; a retrospective cohort study. BMC Health Services Research. 2015; 15: 91. PMid: 25890030. https://doi.org/10.1186/s12913-015-0743-1

[18] Canadian Institute for Health Information. Canadian Coding Standards for Version 2015 ICD-10-CA and CCI. Ottawa, ON: CIHI; 2015 [cited July 25 2018]. Available from: https://secure.cih i.ca/free_products/Coding\%20standard_EN_web.pdf

[19] Elixhauser A, Steiner C, Harris RD, et al. Comorbidity measures for use with administrative data. Med Care. 1998; 36: 8-27. PMid: 9431328. https://doi .org/10.1097/00005650-19980 1000-00004

[20] STROBE Statement-Checklist of items that should be included in reports of cross-sectional studies. [cited July 25 2018]. Available from: https://www.strobe-statement.org/fileadmin/Str obe/uploads/checklists/STROBE_checklist_v4_cross-s ectional.pdf

[21] Dharmarajan TS, Ahmed S. The growing problem of pressure ulcers. Evaluation and management for an aging population. Postgrad Med. 2003; 113(5): 77-8, 81-4, 88-90. PMid: 12764898. https://doi.org/10.3810/pgm. 2003.05.1409

[22] Woodbury MG, Houghton PE. Prevalence of pressure ulcers in Canadian healthcare settings. Ostomy Wound Manage. 2004; 50(10): 22-4, 26, 28, 30, 32, 34, 36-8. PMid: 15509880

[23] Matarese M, Ivziku D, Bartolozzi F, et al. Systematic review of fall risk screening tools for older patients in acute hospitals. J Adv Nurs. 2015; 71(6): 1198-209. PMid: 25287867. https://doi.org/10 $.1111 / \mathrm{jan} .12542$

[24] Hohl C, Karpov A, Reddekopp L, et al. ICD-10 codes used to identify adverse drug events in administrative data: a systematic review. J Am Med Inform Assoc. 2014; 21: 547-57. PMid: 24222671. https://doi.org/10.1136/amiajnl-2013-002116

[25] Stausberg J, Hasford J. Drug-related admissions and hospitalacquired adverse drug events in Germany: a longitudinal analysis from 2003 to 2007 of ICD-10-coded routine data. BMC Health Serv
Res. 2011; 11: 134. PMid: 21619706. https://doi.org/10.118 6/1472-6963-11-134

[26] Ackroyd-Stolarz S, Guernsey J, MacKinnon NJ, et al. The association between a prolonged stay in the emergency department and adverse events in older patients admitted to hospital: A retrospective cohort study. BMJ Qual Saf. 2011; 20: 564-69. PMid: 21209130 https://doi.org/10.1136/bmjqs. 2009.034926

[27] Mion LC, Sandhu SK. Adverse drug events in older hospitalized adults: Implications for nursing practice. Geriatr Nurs. 2016; 37(2): 153-5. PMid: 27036229. https ://doi .org/10.1016/j.gerinu rse.2016.02.006

[28] Trzeciak S, Rivers EP. Emergency department overcrowding in the United States: an emerging threat to patient safety and public health. Emerg Med J. 2003; 20(5): 402-05. PMid: 12954674 https://doi.org/10.1136/emj.20.5.402

[29] Noble DJ, Pronovost PJ. Underreporting of patient safety incidents reduces health care's ability to quantify and accurately measure harm reduction. J Pat Safety. 2010; 6(4): 247-250. https: //doi.org/10.1097/PTS.0b013e3181fd1697

[30] Hougland P, Xu W, Pickard S, et al. Performance of International Classification of Diseases 9th Revision, Clinical Modification Codes as an Adverse Drug Event Surveillance System. Med Care. 2006; 44(7): 629-36. PMid: 16799357. https://doi .org/10.1097/01 .mlr.0000215859.06051.77

[31] Maass C, Kuske S, Lessing C, et al. Are administrative data valid when measuring patient safety in hospitals? A comparison of data collection methods using a chart review and administrative data. Int J Qual in Health Care. 2015; 27(4): 305-313. PMid: 26133382 https://doi.org/10.1093/intqhc/mzv045

[32] Canadian Institute for Health Information, Canadian Patient Safety Institute. Measuring Patient Harm in Canadian Hospitals. What can be done to improve patient safety? [cited July 25 2018]. Authored by Chan B, Cochrane D. Ottawa, ON: CIHI; 2016. Available from: https://secure.cihi.ca/free_products/cihi_cpsi _hospital_harm_en.pdf

[33] Classen DC, Munier W, Verzier N, et al. Measuring patient safety: The Medicare Patient Safety Monitoring System (past, present, future). J Patient Saf. 2016. https ://doi .org/10.1097/PTS. 0000 000000000322

[34] New System Aims To Improve Patient Safety Monitoring. Content last reviewed October 2016. Agency for Healthcare Research and Quality, Rockville, MD. [cited July 25 2018]. Available from: https://www . ahrq.gov/news/blog/ahrqviews/new-syste m-aims-to-improve-patient-safety-monitoring.html

[35] Jha AK, Kuperman GJ, Teich JM, et al. Identifying adverse drug events: development of a computer-based monitor and comparison with chart review and stimulated voluntary report. J Am Med Inform Assoc. 1998; 5: 305-14. PMid: 9609500. https://doi.org/10.1 136/jamia. 1998.0050305 